\title{
Modelling Routeways in a Landscape of Esker and Bog
}

\author{
Yolande O' Brien \\ Department of Archaeology, \\ National University of Ireland, \\ Galway. \\ Email: y.obrien2@nuigalway.ie
}

\begin{abstract}
With the models used in this research, we can identify routeways which can be used to understand landscape and contextualise archaeological remains, while also learning about the decision-making process of people in the past and how they negotiated the landscape. ArcGIS and NetLogo are used to demonstrate the cumulative process which leads to the creation and evolution of routeways over time in a series of actions that approaches efficiency. The environment of North Offaly in the Irish Midlands is used as an example, as it is a landscape of natural routeways and obstacles for which we have rich archaeological and documentary evidence supporting interpretation of movement.
\end{abstract}

\section{INTRODUCTION}

$\mathrm{T}$ HE aim of this research is to understand how people exploited natural routeways and manoeuvred around obstacles in the landscape in the past, using the archaeological evidence from North Offaly in the Irish midlands to explore this question. This research uses modelling and computer applications, augmented by fieldwork and documentary sources, to identify likely routeways.

Two digital approaches are used, namely Least Cost Paths to calculate a routeway, and Agent-Based Modelling to grow [1] one. ArcGIS 9.3 is used, in what is considered a routine method to identify potential routes through the application of Least Cost Paths. NetLogo 5.0.3 [2] has been used to emulate individual actions which lead to the evolution of routeways. While Least Cost Path procedures are ideal for identifying the optimal path through a landscape, the process has access to global information, which is not what agents on the ground experience when attempting to negotiate the landscape. Modelling allows us to investigate the overall evolution of a routeway as individual agents have access only to local information, allowing them to approach the optimal path over time through a process of iterative attempts to traverse a landscape.

The outputs may be used to point to parts of the landscape that merit further research in the field, and comparison of both results to the archaeological and documentary record can improve the parameters in both simulations and help to develop a method which can be used in other study areas for which we do not have such rich records.

This research is funded by the Galway Doctoral Research ScholarshipScheme of the College of Arts, Social Sciences and Celtic Studies, National University of Ireland, Galway

\section{The Study Area}

\section{A. The Landscape of North Offaly}

The landscape of North Offaly (Fig. 1) is dominated with esker, bog and, in the past, extensive natural woodland. An esker is a long, sinuous ridge of sand and gravel, which are the remains of deposits left by rivers of melt-water beneath the surface of glaciers 15,000 years ago. In Ireland, a series of these ridges stretches from the East Coast to the West Coast and are known by the collective name of the Eiscir Riada. Some of the finest examples of high-sided and single-crested eskers are found in the study area (see [3]). The bogs, which are slightly younger, began to form about 10,000 years ago as glacial retreat filled dips and valleys with nutrient-rich meltwater. Poor drainage caused these shallow lakes to build up with partially decomposed plant material and eventually they grew into the typical dome shape of raised peat bogs. The Irish midlands are renowned for their raised bogs, or the Bog of Allen as they are generally known, and a number of archaeological surveys and excavations have demonstrated their importance since early prehistoric times [4], [5], [6]. A stretch of dry land, known as the Midland Corridor [7], bisects this landscape in a northeast by southwest orientation, acting as a major interregional routeway and valuable agricultural land. When Ireland was first populated around 7800BC, the eskers were in already in place and the bogs were in their infancy, so these features would have influenced human activities since the arrival of the first settlers in Ireland.

\section{B. Eskers}

The eskers, being well-drained, elevated, relatively straight and flanked by wetlands, are quite suitable for routeways, as is clear from the large number of trails and roads currently located on these ridges (see Rahugh Ridge, Fig. 8). The early medieval routeway known as the Slighe Mór, which is associated with the birth of King Conn Céadcathach and therefore usually dated to the early $2^{\text {nd }}$ century $\mathrm{AD}$, is defined for much of its course by the Eiscir Riada. From the 


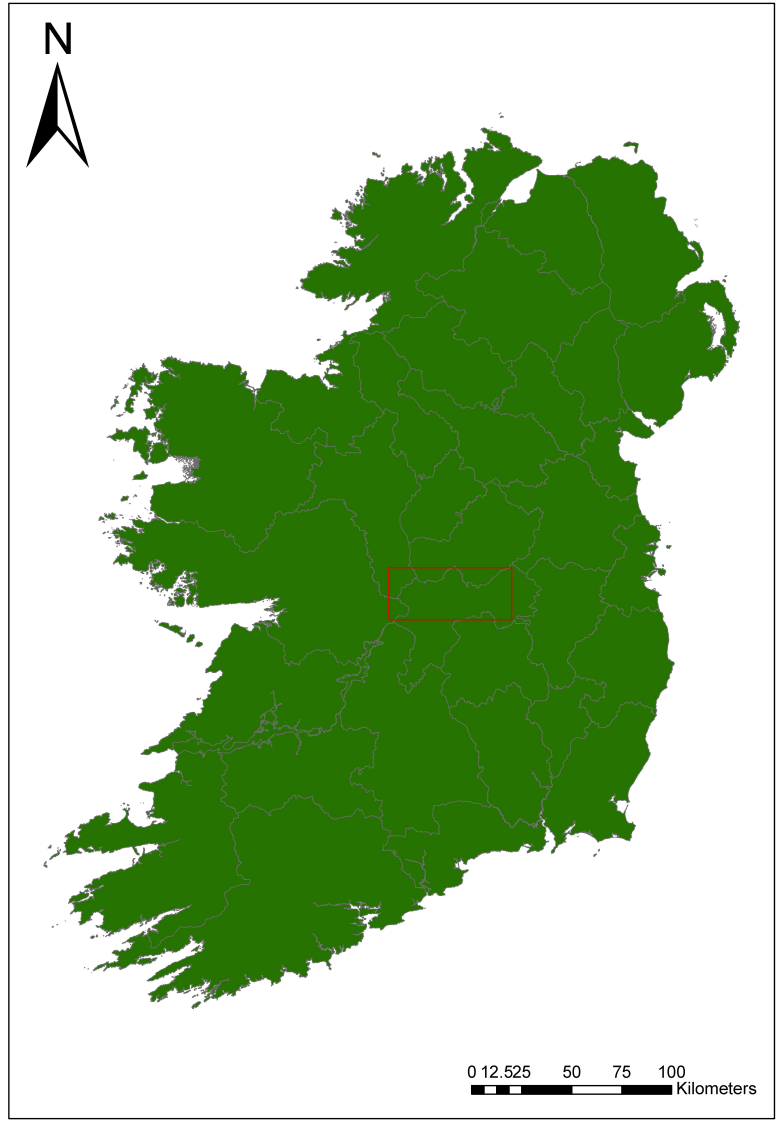

Fig 1: Location of study area

early medieval period on there is a considerable increase in the amount of settlement, particularly ecclesiastical settlement, along the course of the eskers. The presence of a small number of standing stones and burials in proximity to eskers suggest a significance to this feature in prehistory also, but at this time the Midland Corridor with its northeast-southwest axis would have been the more important route. The esker must nevertheless, have been an important local routeway at this time, for negotiating the bogs which would have been even wetter early in their developments.

\section{Bogs}

While bogs are obstacles, they are not necessarily impenetrable if one is prepared to invest energy in the construction of a trackway. Archaeological evidence [4], [5], [6] has revealed a series of timber trackway constructions in these wetland locations, suggesting that there were incentives to traversing the bog, rather than diverting around it using dry land. The principle incentive would have been the saving of time and energy by significantly shortening a journey. Typically, trackways traverse the bog at narrow points, although exceptions exist which are speculated to be for ritual purposes or to access resources within the bog. This means the trackways can be divided into two categories, those crossing the bog which treat it as an obstacle, and those accessing the bog which treat it as an objective.

\section{Hills and Rises}

The terrain throughout the study area is relatively flat, ranging from 40m OD around the River Shannon basin in the West, to $90 \mathrm{~m}$ in the East. Apart from the extinct volcano at Croghan Hill, with a height of $220 \mathrm{~m}$, most rises are quite low, but nevertheless highly visible. These rises often mark the narrowest crossing point across bogs, and they offer a visual cue to anyone traversing the landscape, as well as an ideal vantage point to gauge the terrain ahead.

\section{E. The Slighe Mór}

Documentary itineraries survive which tell us the names of settlements where the Slighe Mór passed [9]. Within the study area, it is known to have passed through Rhode, Croghan, Kiltober, Durrow, Ballycumber, Togher, Ballaghurt and Clonmacnoise. For most of these locations, early ecclesiastical sites have been chosen as nodes between which the models are run.

\section{Methodology}

\section{A. Data}

The map for the study area was produced using Copernicus data and information funded by the European Union EU-DEM layers, with soil information from the Soils and Subsoils Database from the Environmental Protection Agency. Road data is (C) OpenStreetMap and Contributers, CC-BY-SA and the Record of Monumements and Places is (C) Department of Arts, Heritage and the Gaeltacht. I am grateful to Conor McDermott, University College Dublin, for providing survey data from the Irish Archaeological Wetland Unit.

\section{B. Least Cost Paths}

The natural features which create potential routeways or obstacles in this landscape are characterised by soil type more so than slope. The Weighted Overlay tool was used to give soil type a weighting of $75 \%$ and slope a weighting of $25 \%$ to produce a Cost Surface. A scale value of 1 to 10 was applied to each soil type with the following hypothetical values;

\section{Cutover peat -10}

Limestone till - 2

Limestone sands and gravels -2

Basic esker - 1

Alluvium -8

Rock -6

Fen peat -10

Water -10

Lake sediment -10

Made ground -4

Sandstone till -2

Marl - 6

Karstified limestone -6

ArcGIS Least Cost Paths are anisotropic, meaning they are direction dependent. As such, each segment was run in both directions in order to gauge the effect of direction on movement. A realistic path ought to be a hybrid of both of 


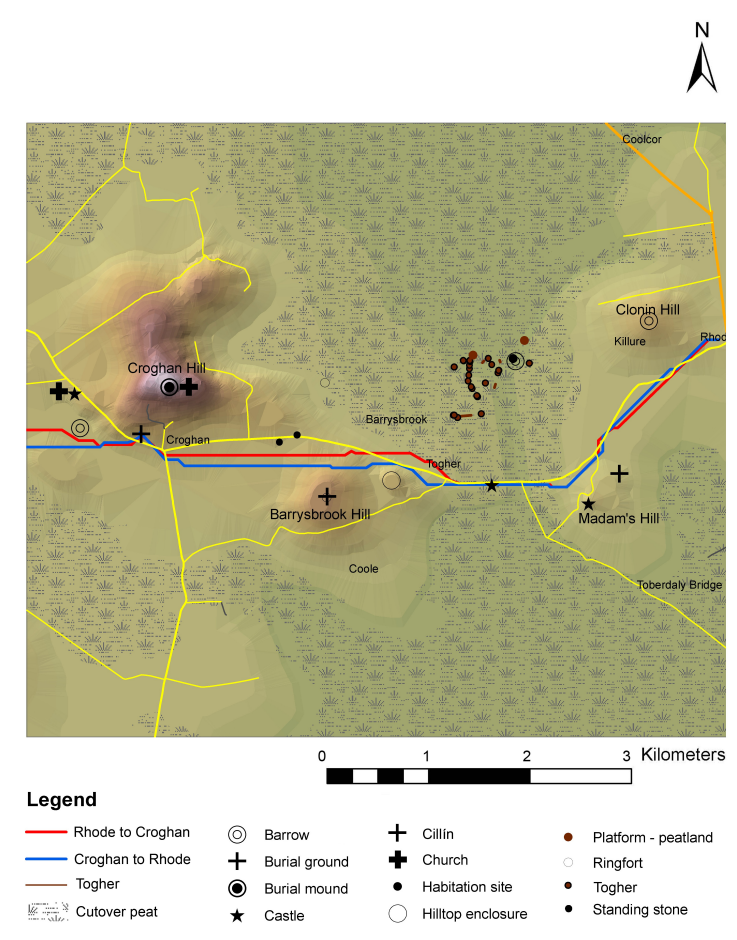

Fig 2: Rhode to Croghan

these paths, but it is not unusual to take a different route depending on direction of travel. Even in the case of established roads, pedestrians often take a different route to and from a location to avoid particular slopes or to maintain a straight course for as long as possible before changing course. It was thus decided to record both results.

\section{Agent-Based Modelling}

The NetLogo GIS extension was used to import the relevant shapefiles to the model, including soil types and elevation data. This model was similarly run in both directions to gain a fuller understanding of the effect of direction on movement. A set number of agents, or turtles in NetLogo terminology, are created at one settlement which is known to have been on the Slighe Mór and told their target is the next settlement.

The leading turtle, or leader breed, turns its heading to its target. Since these settlements are next to significant landscape features such as hills, it was deemed realistic to set a heading in this way from the beginning of the journey, as a traveller in reality would use the hills as visual cues. After setting its heading, the turtle must then negotiate the landscape using a series of simple instructions.

Booleans were used to differentiate between obstacle and not obstacle, with bogs acting as obstacles. When a bog is encountered, the turtle is obliged to find a suitable crossing point by using the in-cone reporter which emulates visual perception in reality to find dry land within a set distance and radius. With this code, the leading turtle can find the most efficient crossing point within a reasonable distance without having to circle the entire bog.
Slope was also considered, with instructions to turn the heading towards the patch with least slope within 2 patches. In this way, steep climbs are avoided and minor corrections are made as the more problematic obstacles are negotiated.

All subsequent turtles, known by the follower breed, are released at regular intervals and they have the same capabilities as the leader to solve any obstacles encountered. They have the advantage, however, of having already had the problem solved by the leader, albeit in an inefficient way. Using the same method as the Ant Lines model [8], each follower turns its heading to its immediate predecessor, while still running its own code to negotiate obstacles and manage slope. This has the effect of smoothing the path over time. Rather than maintaining a heading from the beginning to the opposite settlement, turtles later in the sequence aim straight towards the first solution to an obstacle. This cumulative process approaches an efficient path, as evident from the final turtle matching quite closely the path created through Least Cost Paths.

\section{Rhode to Croghan}

\section{A. Landscape}

The settlements of Rhode and Croghan in northeast Co. Offaly occupy slight elevations which are surrounded by a series of hills of volcanic origin and are separated by Ballybeg Bog (Fig. 2). O' Lochlainn [9] tells us that the Slighe Mór linked these two settlements in the Early Medieval period, so a routeway must have existed between them despite the obstacle of the bog. Clonin Hill, which overlooks Rhode, is topped with a substantial Bronze Age ring barrow, while Croghan Hill is the location of an extremely prominent burial mound. The dating of this monument is uncertain, but the lack of an external ditch would suggest that it is a Neolithic cairn, rather than a Bronze Age barrow. Within the bog itself, the remains of Bronze age settlement and minor trackways which are not designed to cross the bog have been recovered in wetland survey of the area [10], [11]. The presence of prehistoric archaeology at these locations suggests prolonged use of this landscape, which would have required a routeway connecting these sites at an even earlier date than the Slighe Mór is usually dated to.

\section{B. Least Cost Path Results}

The Least Cost Paths predictably traverse the bog at the narrowest point (Fig. 3). This point is flanked by Madam's Hill in Toberdaly, east of the bog, and Barrysbrook Hill to the west. The paths skirt around the lowest slopes of each of these hills avoiding as much as possible the patches of ground with bedrock at the surface, which have a relatively 


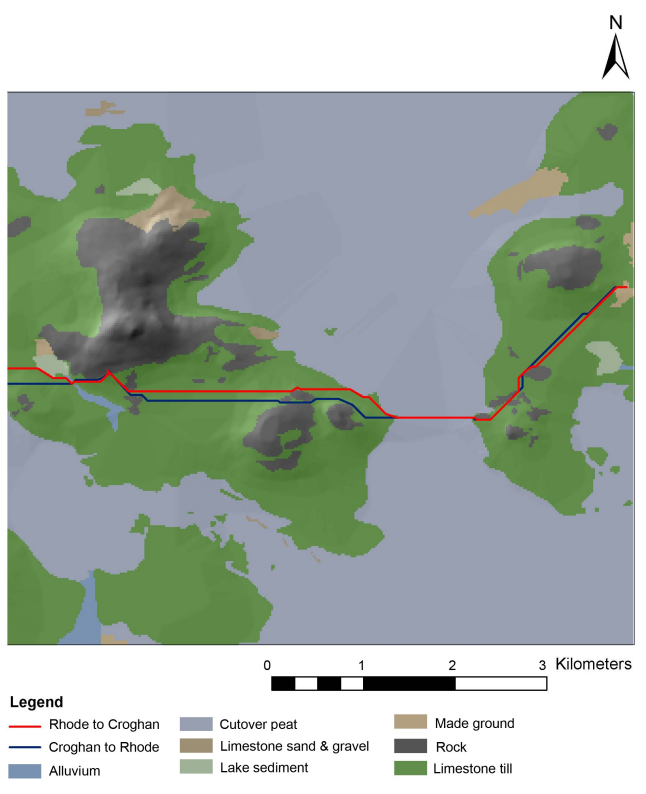

Fig 3: Rhode to Croghan Least Cost Path

high value on the weighted overlay, and which tend also to have increased slope values.

\section{Agent-Based Modelling Results}

A direct path from Rhode to Croghan and vice versa would traverse Ballybeg Bog at an unsuitable crossing point, so the leading turtle is obliged to search for a narrower point, which it finds between Toberdaly and Barrysbrook, just as Least Cost Paths found (Fig. 4). Each follower is able to shorten the path to the crossing point, leading to an eventual path which makes straight for the crossing, with minor corrections made for slope. With the bog crossing complete, the remainder of the trip is unimpeded and a relatively straight route can be taken to the objective.

\section{Archaeological Evidence}

This path taken by both programs through Ballybeg Bog coincides with the existing roadway which crosses this obstacle. A map dating to c. 1563 (Fig. 5) illustrates this crossing point, a causeway between Cnocarderin and a se-

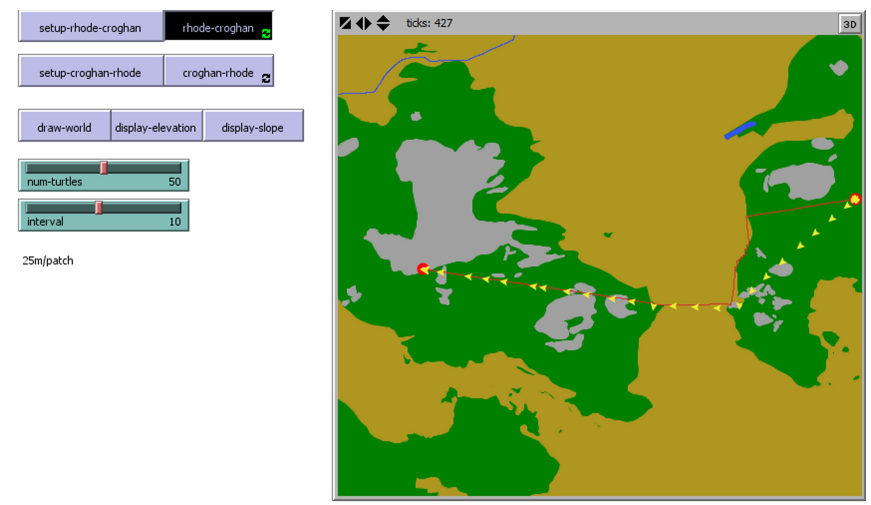

Fig 4: NetLogo model - Rhode to Croghan ries of hills East of Croghan. The feature is labelled as a togher and defended by a castle, demonstrating the strategic importance of this crossing. The Togher of Croghan, or Tóchar Cruachain Brí Éile, is mentioned in the Annals at least as early as 1385 , so the current roadway, and the path suggested by the modelling, mark a crossing of some antiquity. Given the prehistoric archaeology in the area, it would be likely that this crossing would have been exploited at an earlier date also.

The section of road linking the togher with Croghan is $19^{\text {th }}$ century in date but it matches the path predicted by both modelling procedures and happens to have been flanked by two standing stones. An older road circles south of Barrysbrook Hill, before meeting a crossroads which can be taken back towards Croghan. When walking this routeway, it is clear that the series of hills which make up this landscape (Clonin Hill, Madams Hill, Barrysbrook Hill and Croghan Hill) create visual cues which one aims towards when navigating the terrain. In particular, the target generally seems to be towards a low point on the slope, offering a suitably dry area for comfortable walking without an unnecessarily high climb, and providing an ideal vantage point to view the ground ahead. With this in mind, it would make no sense to move south of Barrysbrook Hill to reach Croghan. This path would only make sense if one was bypassing Croghan in favour of Kilclonfert, another ecclesiastical settlement which was reputedly on the Slighe Mór [12].

This author would suggest that the standing stones, the models and the trajectory which the landscape impresses on a traveller through visual cues is sufficient to seriously consider the presence of an older routeway between Barrysbrook Hill and Croghan Hill. Perhaps any earlier routes through Croghan Demesne would have been discouraged it is clear that older road south of Barrysbrook Hill skirts around the grounds of the townland of Croghan Demesne.

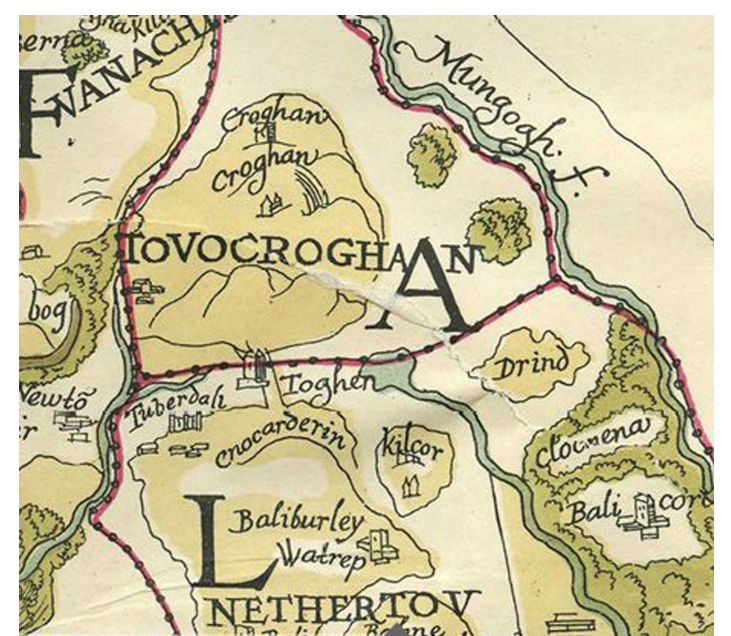

Fig 5: Togher of Croghan. With permission (C) The British Library Board. Cotton Augustus MS I ii 40. North to right of image. 


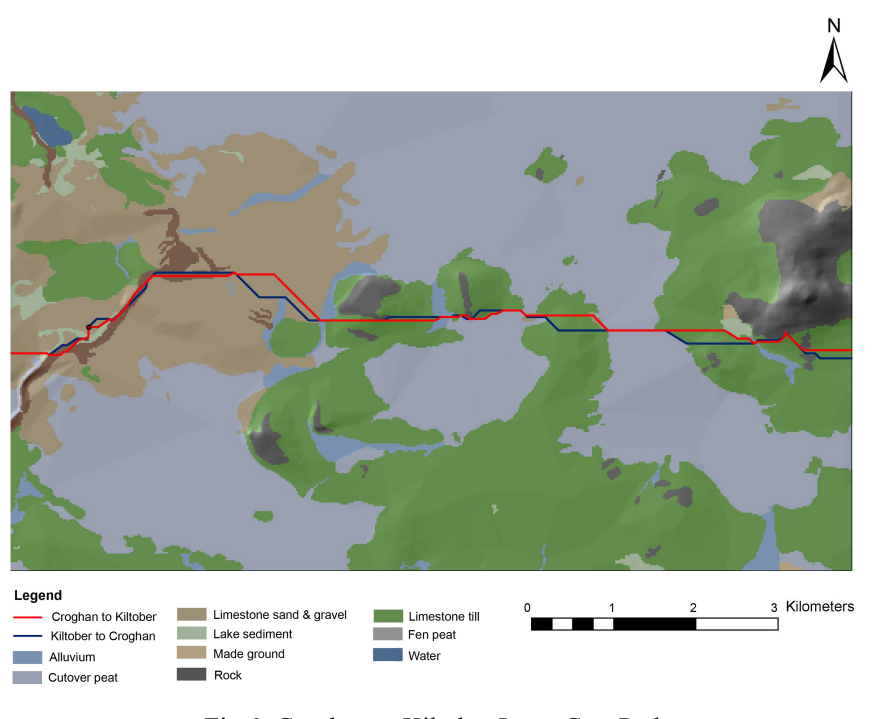

Fig 6: Croghan to Kiltober Least Cost Path

\section{Croghan to Kiltober}

\section{A. Landscape}

Kiltober townland is largely composed of limestone sands and gravels with the very substantial Rahugh esker creating the southeastern border (Fig. 6). This is a particularly significant part of the Slighe Mór as it marks an intersection with the Midland Corridor. The importance of this intersection is demonstrated by the distribution of barrows in prehistory and ringforts in the medieval period, with particular emphasis on areas with limestone sand and gravel subsoil.

Clonearl Bog and Raheenmore Bog are located between Croghan and Kiltober, and these must be negotiated to move between the settlements. Just as in the previous segment, a series of low hills are present at Oldcroghan, Kilduff, Clonagh and Mullagharush Hill and they mostly flank the narrowest points of the bogs.

\section{B. Least Cost Path Results}

The Least Cost Paths for this segment similarly traverse the bogs at the narrowest points available without deviating course more than a few degrees (Fig. 6). Clonearl Bog is crossed at a narrow point on its northern extent, between rises at Oldcroghan and Kilduff. Raheenmore Bog narrows to only 10m East of Clonagh Hill, and the paths skirt the southern base of that rise and Mullaghrush Hill. The hills mark the most convenient crossing points, but they are only climbed as much as is necessary to gain dry land. The esker is climbed at a suitably gentle point on its northeastern extent, after which this level, single-crested esker leads directly to the Kiltober.

\section{Agent-Based Modelling Results}

The journey from Croghan to Kiltober requires the crossing of Clonearl Bog and Raheenmore bog (Fig. 7). The leader finds the narrowest points in these bogs, which is

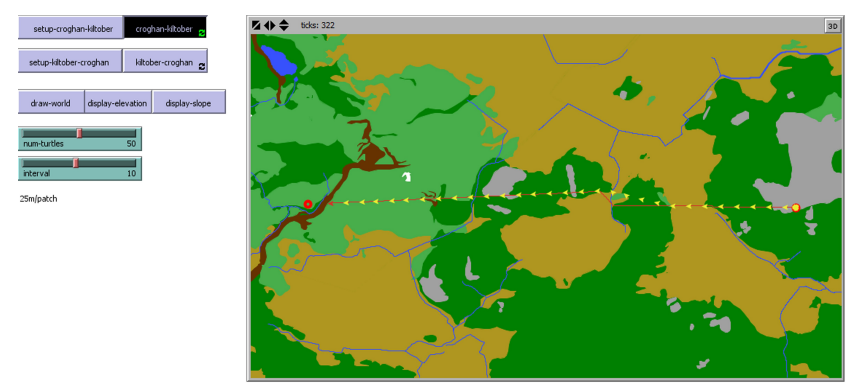

Fig 7: NetLogo model - Croghan to Kiltober exactly the same point which Least Cost Paths identified as the most efficient route. The model differs significantly from the ArcGIS version on the Western extent where the esker is accessed. The model does not give preference to the esker and climbs it c. $1 \mathrm{~km}$ South of the Least Cost Path. This esker has been used as a road, with two castles situated along its course, one being a motte and bailey castle which dates to the late $12^{\text {th }}$ or early $13^{\text {th }}$ century, suggesting lengthy use of this esker as a road. It is clear then that eskers are more important in the placement of roads than slope alone would suggest. This is down to their elevation and the composition of the subsoils, which are well-drained and ideal for use as a pathway. This supports the preferential weighting given to eskers in the Weighted Overlay in ArcGIS.

\section{Archaeological Evidence}

Clonearl Bog is most recognised for the Iron Age bog body found there in 2003. Oldcroghan Man, as he is known, was found $1.3 \mathrm{~km}$ Southeast of the proposed crossing, where the bog is at its widest. As discussed above (II D), activities in the bog can be separated between those which treat the bog as an obstacle and those which treat it as an objective. The deposition of Oldcroghan Man was a ritual activity and it is no surprise that it should take place in a different location to simple negotiation of an obstacle, but it is a good indication for activity in the environment, from which we can assume movement was taking place.

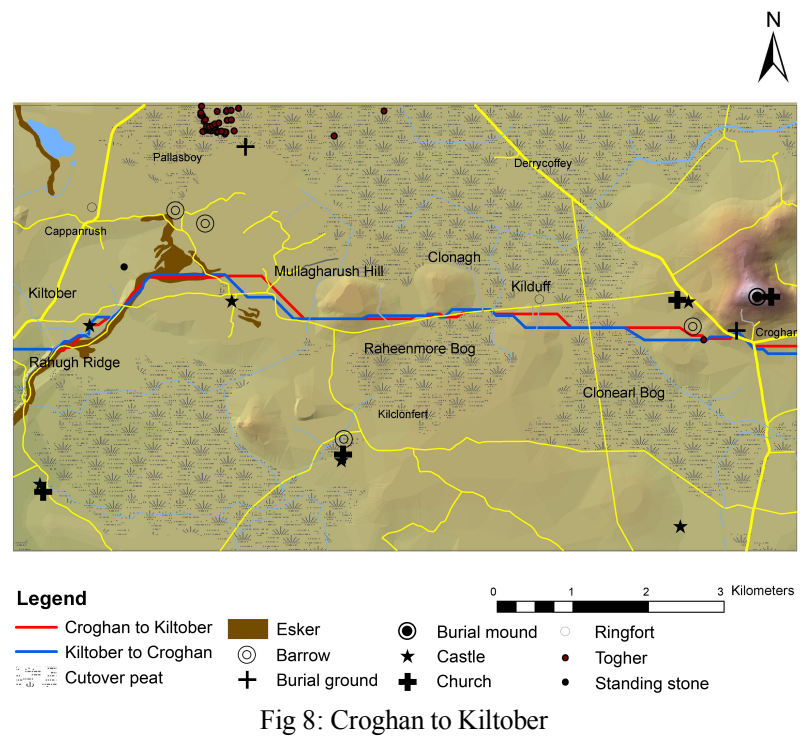

The predicted paths closely correlate with existing roads at the Raheenmore Bog crossing and along the southern slopes of Clonagh and Mullagharush Hill (Fig. 8). While the existing road climbs the esker $0.5 \mathrm{~km}$ South of the Least Cost Path prediction, they maintain a very similar course to the target.

A standing stone and several barrows are in close proximity to the esker on its west side. These are part of the cluster of barrows which mark where the Midland Corridor enters into the ancient kingdom of Leinster and are more closely associated with that route rather than the esker. With 
only a few exceptions however, this esker delimits the extent of this distribution. The orientation of this esker is unusual as most examples in Offaly are of an east-west orientation. This unusual esker is therefore acting as a wrapping mechanism, delimiting the Midland Corridor and the barrow distribution, as well as representing the crossing point of two important routeways.

\section{Discussion}

Those natural features which are conducive to movement must be exploited and established in the mental map of individuals before they can truly be called routeways. While ArcGIS can effectively show us the end product and a potential routeway, NetLogo shows how routeways are established through a series of discrete actions around those natural features, acted out by individual agents over time. The ability of agents to effectively learn from their predecessors through the use of the Ant Lines model, allows for quicker problem-solving on the part of the individual and more efficient paths than initial attempts would produce.

In real world problem-solving, this would appear as a series of trails which impress upon any subsequent traveller. If an opportunity arises to smooth the trail through cutting corners it is usually done, as is evident in the elaborate network of desire lines which can be seen in managed parklands or city green areas. The most efficient path becomes the most established one both mentally, through repeated experiences, and physically, through repeated use and perhaps even enhancement through construction. In this way, a stable macrostructure emerges from the interaction of local agents and feedback from microstructures [1].

Both Agent-Based Modelling and Least Cost Paths reflect different facets of the theoretical approach of this research. Complex systems can be derived from a variety of factors involving simple rules and no centralised control. Energy and physical factors which GIS handle so well are crucial in this, but experiential concerns and other qualitative factors ought also to be considered in the emergence and development of routeways and subsequent networks.

\section{CONCLUSION}

The use of these methodologies allows us to not only hypothesise the position of paths in the landscape, but to understand the processes which lead to their creation. Having done so, we can compare predicted paths with existing roads to identify the locations which merit further research archaeologically. Archaeological monuments in proximity to these paths can be better understood as part of their overall landscape by understanding how they fit into the existing system of routeways. The segments discussed have included portions which were important enough to have warranted castles to protect them, such as the Togher of Croghan, while the presence of prehistoric archaeology throughout each example demonstrates the necessity of routeways from the earliest settlement in this area. Viewing these monuments in a movement-centric framework has helped to place them into the context they would have been experienced in the past.

\section{REFERENCES}

[1] J. M. Epstein, Growing Artificial Societies: social science from the bottom up. Brookings Institution Press, 1996.

[2] U, Wilensky, NetLogo, http://ccl.northwestern.edu/netlogo/. Center for Connected Learning and Computer-Based Modelling, Northwestern University, Evanston, IL, 1999.

[3] M. Tubridy and R. Meehan, County Offaly Esker Survey 2006. Offaly County Council, 2006.

[4] B. Raftery, Trackway Excavations in the Mountdillon Bogs, Co. Longford, 1985-1991. Dublin: Crannóg Publications, 1996.

[5] J. Whitaker and E. O' Carroll, Peatland Excavations 1999-2000: Lemanaghan Group of Bogs, Co. Offaly. Dublin: Archaeological Development Services, 2009.

[6] J. Whitaker, Peatland Excavations 2001-2002: Mountdillon Group of Bogs, Co. Longford. Dublin: Archaeological Development Services, 2009.

[7] A.P. Smyth, Celtic Leinster: towards an historical geography of early Irish civilisation, AD 500-1600. Dublin: Irish Academic Press, 1982.

[8] U. Wilensky, NetLogo Ant Lines model, http://ccl.northwestern.edu/netlogo/models/AntLines. Center for Connected Learning and Computer-Based Modelling, Northwestern University, Evanston, IL, 1997.

[9] C. O' Lochlainn, "Roadways in Ancient Ireland", in Féil Sgríbinn Éoin Mhic Néill. Dublin: 1940, pp. 465-474.

[10] C. Murray, 'Ballybeg Bog, Barrysbrook/ Clonin/ Toberdaly/ Togher', http://www.excavations.ie/Pages/Details.php? Year=\&County=Offaly\&id=7044, Dublin: Wordwell.

[11] J. Whitaker, 'Lanespark, Ballybeg and Derryvella Bogs, Derryvella/ Glengoole North/ Lanespark/ Poynstown' http://www.excavations.ie/Pages/Details.php? Year $=\&$ County $=$ Tipperary\&id $=16650$, Dublin: Wordwell.

[12] E. Fitzpatrick and C. O' Brien, The Medieval Churches of County Offaly. Ireland: Government of Ireland, 1998. 